\title{
Carnets
}

Revue électronique d'études françaises de l'APEF

Première Série - 1 Numéro Spécial | 2009

Cultures littéraires : nouvelles performances \& développement

\section{Le Temps découpé de Michel Butor: um exemplo da escrita de experimentação}

\section{Francisco Sousa Neto}

\author{
(2) OpenEdition \\ Journals \\ Edição electrónica \\ URL: http://journals.openedition.org/carnets/4129 \\ DOI: 10.4000/carnets.4129 \\ ISSN: 1646-7698 \\ Editora \\ APEF
}

Edição impressa

Data de publição: 1 Junho 2009

Paginação: 341-349

Refêrencia eletrónica

Francisco Sousa Neto, «Le Temps découpé de Michel Butor: um exemplo da escrita de

experimentação », Carnets [Online], Première Série - 1 Numéro Spécial | 2009, posto online no dia 16 junho 2018, consultado o 23 abril 2019. URL : http://journals.openedition.org/carnets/4129 ; DOI : $10.4000 /$ carnets. 4129 


\title{
LE TEMPS DÉCOUPÉ DE MICHEL BUTOR: \\ Um exemplo da escrita de experimentação
}

FRANCISCO SOUSA NETO

FCT/Universidade Aberta

francisco.sousa.neto@gmail.com

\section{Resumo}

A presente reflexão pretende abordar um caso de Literatura enquanto espaço de criação, cooperação/colaboração e inovação, centrando-se na singular e original obra Le Temps Découpé, produção que mistura as colagens do artista belga Thierry Renard com os textos de Michel Butor. Perante a riqueza e multiplicidade reveladas por esta produção a quatro mãos, o leitor deverá desempenhar não apenas o papel de simples consumidor, mas sobretudo o de produtor. Este texto constituirá, deste modo, um pretexto para a reflexão sobre a relação entre o escritor-filósofo Butor e o leitor/co-produtor. Constataremos, finalmente, que a obra de Butor apresenta uma questionação violenta dos conceitos de Arte e de Literatura, uma vez que recusa a comunicação imediata e transgride a disposição tradicional do livro, designadamente ao relacionar-se, de forma inovadora, com outros espaços artísticos.

\begin{abstract}
This paper issues the presentation of a Literature case as a space of creation, cooperation/collaboration and innovation, focusing in the singular and original novel Le Temps Découpé, production that joins the works of the Belgian artist Thierry Renard to the texts of Michel Butor. Through the multiplicity and richness presented in this four hands writing, the reader should not only act the final role as a simple consumer, but he must act like a producer. This text constitutes in its own way a subject of reflection about the relation between the writer-philosopher Butor and the reader/co-producer. Finally it will be analyzed that Butor novel assumes a profound and violent interrogation of the concepts of Art and Literature, because it refuses the immediate communication and transgresses the traditional disposition of a book, specially in its relations, in a innovation way, with other artistic spaces.
\end{abstract}

Palavras-chave: Michel Butor, Modernidade, Transgressão, Escrita de experimentação, Colaboração inter-artística

Keywords: Michel Butor, Modernity, Transgression, Experimental writing, Inter-artistic collaboration 
A escrita de Michel Butor (1926-) - autor conhecido pela sua actividade incessante e pelo seu pouco gosto pela facilidade - é caracterizada por uma exploração constante de novas estruturas e pela multiplicação dos processos de construção, nomeadamente através da publicação de certas obras em colaboração com artistas plásticos, como é o caso na obra Le Temps Découpé. Nesta perspectiva, e tendo em conta a afirmação barthesiana segundo a qual "[...] l'enjeu du travail littéraire c'est de faire du lecteur non pas un consommateur, mais un producteur de texte" (BARTHES, 1970: 66), perante a multiplicidade, a riqueza e a dificuldade do texto de Butor, o leitor deverá desempenhar um papel mais activo: mais do que um simples consumidor, ele tornar-se-á sobretudo num produtor. Dado que a natureza dessa recepção-interpretação-produção relativamente à obra Le Temps Découpé será, sem dúvida, muito variada, dependendo do tipo de leitor que tem acesso ao livro, optámos por dividir a nossa exposição em três partes:

1) Inicialmente, experimentaremos uma interpretação mais tradicional - e porventura superficial —, uma vez que estreitamente relacionada com o(s) 'tema(s)' do livro e que intitulámos "Uma 'temática' conhecida e reconhecível".

2) De seguida, tendo em conta a forma como o livro está construído, abordaremos a questão da modernidade e originalidade da obra (com o objectivo de mostrar que o modo de tratamento dos temas não tem nada de tradicional). Esta parte designar-se-á "A construção da obra e os processos da modernidade: originalidade e riqueza do texto".

3) Por fim, faremos alusão a Butor e ao seu leitor - do bricoleur (que é o escritor-filósofo) ao co-produtor-(re)criador (em que se transforma o leitor, mercê da intervenção mais activa que lhe é solicitada).

\section{Uma 'temática' conhecida e reconhecível}

Não obstante a singular e inovadora apresentação da criação Le Temps Découpé obra que mistura as colagens do artista belga Thierry Renard (1951-) com os textos de Michel Butor (inspirados ora nas colagens, ora nos títulos das mesmas) —, um leitor menos familiarizado com a literatura de vanguarda em geral e com a produção literária de Butor em particular será facilmente seduzido por uma análise (essencialmente) temática do livro. Com efeito, partindo do título da obra e da colagem da capa (que reproduz, de forma bastante recortada, uma silhueta feminina), podemos eventualmente antecipar um livro que fale da condição humana, condição essa que é marcada pela fragilidade e pela efemeridade, designadamente a da mulher. Esta interpretação poderá ser explicitada, não sem controvérsia, pela ideia de anonimato gerada pela ausência de olhos e rosto na silhueta 
apresentada na capa ${ }^{1}$ e pela associação, no título, do adjectivo "découpé" ao nome "temps" (além de reenviar para as colagens, este vocábulo poderá introduzir a ideia de que o tempo humano é desperdiçado — de forma acidentada, irregular).

Esta análise temática centrada na efemeridade da condição humana parece ser corroborada em várias passagens desta produção "a quatro mãos" de que destacamos os seguintes exemplos:

1) a utilização de um campo lexical da rapidez (bastante importante no universo de Butor), da passagem célere do tempo ("collage-clin-d'œil”, "en devenir", "glissent”, "à l'heure de la dérive", "survolées", ...) no prefácio "Image(s)" (BUTOR, 1991: 7) , redigido pelo autor das colagens.

2) a oposição apresentada pelo texto que acompanha a colagem La mémoire des lieux (idem: 8) entre o relógio e o Homem. Enquanto o relógio (associado ao "poder" e a uma "deusa implacável") é o símbolo do tempo que passa muito depressa e nunca se repete, o Homem é a vítima da acção nefasta do tempo, como demonstram as palavras "sacrifices" e "sang" que lhe são associadas.

3) a antinomia presente no poema em prosa inspirado na colagem With fairest flowers (idem: 18) entre o campo lexical da vida ("boutons", "ouverture des pétales", "matin", "oiseaux chanteurs") e o campo lexical da morte ("leur chute", "la neige l'hiver sur les tiges dépouillées") ${ }^{2}$. No entanto, a utilização de expressões temporais ("Souvent le matin", "Chaque année"), conduz-nos à ideia de ciclo da natureza (que se renova todos os anos) em oposição à efemeridade da condição humana (tocada por uma evolução irreversível).

4) a alusão, no texto escrito para a colagem Devant le temps qui court (idem: 22) à passagem do tempo e à necessidade de refazer as criações da humanidade ("Rayée la journée, à refaire, il faut repartir sur de nouvelles bases").

5) o diálogo imaginado para as duas figuras femininas da colagem Regards Croisés (idem: 30 ) que põe em evidência alguma das consequências nefastas da passagem do tempo e a consciência da perda (inevitável) da beleza/elegância ("Si vous saviez ce que vous deviendrez dans quelques années").

Ainda que, numa primeira abordagem, o leitor (tradicional) possa associar esta produção à insistência na ideia de passagem e ao carácter transitório e cíclico dessa passagem, o recurso a frases bastante enigmáticas e a jogos de palavras pode funcionar como um alerta, como um piscar de olhos para que o leitor mais proficiente não se centre exclusivamente no aspecto temático, mas sobretudo na estrutura da obra. A verdade é que

\footnotetext{
${ }^{1}$ Dessa ideia de anonimato, poderemos tirar a ilação de que somos todos iguais no que se refere à fugacidade da vida, sendo a nossa alma prisioneira - como parecem querer revelar as riscas/'grades' da colagem — do corpo e escrava das aparências.

${ }^{2}$ Convém destacar, no mesmo texto, a presença de um estado intermédio, patente nas "quelques feuilles encore accrochées" (idem: ibidem), que representam a esperança, a resistência à fatalidade da morte.
} 
estamos numa época em que o estatuto do livro mudou enormemente: o livro é doravante um objecto físico e o livro ilustrado assume extrema importância ${ }^{3}$. Deste modo, a análise desta produção a duas vozes, onde a imagem-colagem inspirou a imagem textual, revelar-se-á certamente mais 'válida' quando o leitor tiver em conta o novo estatuto do livro e a sua relação com a modernidade da obra em estudo.

\section{A construção da obra e os processos da modernidade: originalidade e riqueza do texto}

Segundo Sylvie Abraham, na escrita de Butor, "ce n'est donc plus la question du quoi qui importe et moins encore celle du pourquoi: Michel Butor s'interroge et nous interpelle sur la question du comment' (ABRAHAM, s/d: 152) ${ }^{4}$. Atentemos, pois, no modo de elaboração do livro Le Temps Découpé, para posteriormente nos referirmos aos processos novos de que o autor se serviu.

Como mencionámos já, este livro ilustrado que apresenta um rectângulo de dupla página é o resultado de uma cooperação/colaboração muito íntima entre o escritor Michel Butor e o colagista Thierry Renard: vinte e cinco colagens do artista belga (com título e data atribuídos por ele próprio) foram entregues ao escritor-viajante para que este produzisse a partir delas pequenos poemas em prosa. Estamos perante uma estreita colaboração entre Literatura e Pintura, visto que se trata de um livro com dois pais (um pai-texto e um paicolagem), um livre d'artiste. Esta forma de diálogo terá sido muito enriquecedora e estimulante para a imaginação de Michel Butor. Com efeito, o próprio autor de L'emploi du Temps reconhece: “il y a toute sorte de choses que je n'aurais jamais écrites si je n'avais pas été incité par la collaboration" (BUTOR, 1984: 15).

Por outro lado, por detrás da organização aparentemente simples e linear do livro (prefácio seguido da sucessão texto - imagem, texto - imagem), surge uma obra hermética, opaca e petrificante, como é típico dos textos de Michel Butor. Parece contribuir para este hermetismo, a utilização de uma linguagem difícil, bem ao gosto do escritor-filósofo, semeada de algumas palavras raras $^{5}$ (que normalmente não se repetem para não perderem o seu poder) e de numerosas referências intertextuais e culturais ${ }^{6}$ que exigem do leitor um saber muito vasto (cf. BuTOR, 1984: 11) - Pintura $^{7}$, Literatura ${ }^{8}$, Cinema ${ }^{9}$, História,

\footnotetext{
3 Parece oportuno relembrar que Butor chega a afirmar: "aujourd'hui [...] le livre normal est le livre illustré" (BUTOR, 1993: 209); "Le livre sans illustration est désormais une anomalie, la survie d'une forme antérieure" (idem: 210).

7 A colagem "Les heures claires" (ButoR, 1991: 41) contém parte da tela «L'église d'Auvers» de Van Gogh e uma das figuras de "Regards croisés" (idem: 31 ) pertence ao «Portrait de Juliette Récamier» de Jacques-Louis David.
} 
Geografia $^{10} \ldots$ são apenas alguns domínios abrangidos pelo livro. Esta diversidade é o resultado da enorme colaboração/cooperação em que se envolve o autor de Passage de Milan, não só com outros artistas (neste caso, Thierry Renard), mas também com outros textos $^{11}$ e com outras práticas ${ }^{12}$.

Apesar da importância que Butor atribui à linguagem literária quando afirma que "[...] les différents types d'art n'existent que par le discours. On introduit le langage dans une image picturale pour lui donner un sens, pour la comprendre, pour la traduire même" (BUTOR, 1993: 207), os textos acabam por transformar o verdadeiro sentido das colagens. Esta modificação de sentido leva Thierry Renard a afirmar que "certains poèmes suggèrent d'autres choses que celles que j'y avais mises" (RENARD, 2000) e vai ao encontro das reflexões de Butor sobre a relação pintura-escrita: "La simple description d'un tableau le change" (BUTOR, 1993: 218); "Le texte transforme le tableau en film" (idem: ibidem); "Ce que j'écris va non seulement transformer la signification de ce que je regarde, mais son équilibre plastique, sa composition même" (idem: 226).

Esta transformação resultará também da abolição de fronteiras, da fusão irónica de todos os universos perpetrada pelas reflexões de Butor sobre a alteridade dos lugares e das culturas $^{13}$. Tal visão universalista decorre, certamente, da paixão de Butor pelas viagens paixão essa que o leva a sonhar "estar em todo o lado ao mesmo tempo"14 - e do seu imaginário cosmopolita e transcultural. Para apresentar ao leitor este universo paradoxal, o escritor procedeu a uma enorme pesquisa em termos lexicais, o que the permitiu pôr em prática um vocabulário muito rico, uma gramática inédita, em suma, um discurso que nos faz

\footnotetext{
${ }^{8}$ Registe-se a alusão a Dante e Beatriz no texto que acompanha a colagem "Souvenir de première communion" (BUTOR, 1991: 48) e a expressão "Miroir, gentil miroir" (a propósito da colagem "Tu n'écouteras point l'orage" idem: 46), decalque de uma passagem do conto Branca de Neve e os Sete Anões.

9 Atente-se na referência aos "comiques de service" do "temps du muet et du noir et blanc", Bucha e Estica (Laurel e Hardy), presentes na colagem "Souvenir de première communion" (BuTOR, 1991: 48).

10 Nos seus textos, Butor insere também as suas experiências de viagem, a sua "veine baladeuse", a sua atracção pelos longínquos.

${ }^{11}$ Cf. supra nota 8.

12 Butor convocou na sua escrita outras práticas relativas às artes, como confirmam os seguintes exemplos: o vocábulo "peinte" (BUTOR, 1991: 18) e a expressão "des arbres de peinture" (idem: 26) reenviam para a pintura; "Taillée" (idem: 54) remete para a escultura; "le temps du muet et du noir et blanc" (idem: 48) e "reconstitution hollywoodienne" (idem: ibidem) para o cinema; "recoller" (idem: 36) para a actividade do colagista; "La porcelaine du paysage romantique" (idem: 36 ) faz pensar tanto na pintura como na escultura.

${ }^{13}$ Esta fusão de mundos diferentes, esta abolição de fronteiras pode ser constatada em diversas passagens do volume Le Temps Découpé. Deste modo, a propósito da colagem Droit de regard (BuTOR, 1991: 11), temos um texto que põe em cena a confusão dos sentidos. Similarmente, a Basílica "désaffectée" (idem: 14) que permite os "plaisirs de la navigation aérienne" (idem: ibidem) e a disposição da "collation dans les anciennes sacristies" (idem: ibidem) torna-se, através de um processo de subversão da função da basílica, "la cité idéale" (título da colagem). Esta união de mundos variados pode tomar formas mais misteriosas e curiosas, como a que nos apresenta a frase: "Les tasses de thé se sont effeuillées en pétales qui tournoient encore dans le silence des vacances" (idem: 24) Noutros casos, é a última frase destes textos que é frequentemente muito enigmática e constitui um bom exemplo de ironia ou de ambiguidade: "Et le lendemain, tout le monde est satisfait" (idem: 34); "Les spécimens les plus recherchés comportent des oiseaux chanteurs" (idem: 18). Todos estes textos decorrem necessariamente do imaginário cosmopolita e transcultural de Michel Butor.

${ }^{14}$ Parece oportuno destacar duas paixões que se alimentam mutuamente: "Je voyage pour écrire, j'écris pour voyager" (BUTOR, s/d: 223).
} 
duvidar das categorias tradicionais e que o leitor nem sempre consegue decifrar ${ }^{15}$. De facto, o que importa nos textos de Butor não é o relato de uma narrativa ou acontecimento (quase inexistentes), mas o fascínio pelo dicionário e pelo poder da palavra, a associação e sucessão de palavras, aspecto que torna os textos muito polissémicos e muito plurais à leitura e a sua obra um verdadeiro grimoire (obra indecifrável, com um discurso ininteligível, obscuro). Este trabalho de Butor com as palavras faz dele um bricoleur, um carpinteiro da linguagem ${ }^{16}$ e um exemplo da busca artística nos séculos $X X$ e XXI, produzindo textos que, como Le Temps Découpé, rompem com a linearidade tradicional do texto literário e acedem a um modelo novo que se dirige para um certo fragmentarismo (de que a bribe - citação não identificada — é um exemplo).

\section{Butor e o seu leitor - uma estética da re-criação}

No artigo "Buturoscope", o autor de L'emploi du Temps reconhece: "Mon obsession c'est de regarder ce qu'on ne me montre pas" (GAUDEMAR, 1996: III); "Je sens qu'il y a des choses voilées, mes lecteurs doivent m'aider à les éclaircir" (idem: ibidem).

Estas afirmações traduzem um apelo ao leitor para que ele desempenhe um papel activo no sentido de produzir ele próprio a sua leitura. Para compreender o texto de Butor, o leitor será naturalmente esclarecido por outras leituras que fez e sempre que ler o livro poderá elaborar análises intelectuais distintas, tendo em conta a pluralidade de interpretações que este livro inesgotável parece autorizar. Podemos mesmo comparar a interpretação desta escrita à música: cada vez que se reproduz uma canção, obtemos uma nova produção. A releitura contínua que parece ser possibilitada por alguns textos permite-nos afirmar que a obra nos desperta e prepara para a leitura do livre d'artiste com todo o seu lado inclassificável, com todo o seu aspecto de OLNI (Objecto Literário Não Identificado). A dificuldade em encontrar o sentido para alguns textos deriva provavelmente do interesse do escritor-professor pela cuisine des mots. Caberá ao leitor dar um sentido a esses textos, o que faz com que ele se torne um co-produtor da obra. Podemos, a este propósito, anotar exemplos de outras obras que se inserem nesta escrita, escapando por isso a qualquer classificação tradicional:

- Mobile, em que se verifica uma abolição da fronteira produtor/receptor;

- Votre Faust, ópera criada com o compositor Henri Pousseur;

\footnotetext{
${ }^{15}$ A propósito da colaboração com outros artistas, Butor afirma: "cela a tellement contribué à la multiplication de mon imagination que beaucoup ont eu du mal à me suivre” (BuTOR, s/d: 224).

${ }^{16}$ Ele reúne elementos que vêm de diferentes lugares e inventa coisas novas, parte de citações (não indicadas, não há notas nos seus livros), de ideias antigas (a prática da reconstrução de texto) e dá-lhes uma nova vida, uma nova dignidade. Estamos perante uma espécie de reciclagem.
} 
- Réseau Aérien, experiência radiofónica em que a escrita se conjuga com aviões de reacção;

- 6810000 litres d'eau par seconde, estudo estereofónico a duas vozes - um leitor, um locutor — aplicado ao som da catarata de Niágara;

- Dialogue avec 33 variations de L. van Beethoven sur une sonate de Diabelli (uma variação poética);

- Brassée d'avril, com três guaches de Vieira da Silva;

- Naufragés de l'Arche, com 84 fotografias de Pierre Bérenger.

Estamos, pois, perante uma nova forma de colaboração: o apelo à interpretação do leitor. A obra de Michel Butor — que a dada altura confessa: "Quand j'écris, j'ai besoin des autres, j'ai besoin des lecteurs" (BuTOR, s/d: 122) - depende de uma "esthétique qui implique une véritable collaboration créatrice du lecteur et [...] invite ce dernier à participer avec lui à la mise en équation du monde" (LEMAITRE, 1994: 148). O processo de "leitura" do livro é este porque os livros de Butor "doivent être tenus non pour des 'produits finis', mais pour des 'procédures productrices' qui lui montrent le chemin à suivre et le constituent, bon gré mal gré, en producteur de texte" (BELZANE, 1996: 66).

Deste modo, Butor transgride um verdadeiro tabu: "la figure sacrée de l'Auteur" (idem: 65), uma vez que ele não escreve para leitores, mas para escritores, "pour l'écrivain qui est en chacun de nous". (idem: ibidem)

\section{Conclusão}

Segundo Sylvie Abraham, quatro quintos da obra de Michel Butor escapam ao romance e mesmo a qualquer classificação (cf. ABRAHAM, s/d: 151). Com Butor assiste-se, além disso, a uma relativização e questionação violenta do próprio conceito de arte e de literatura: a obra de Butor desconcerta e decepciona (cf. BELZANE, 1996: 61), na medida em que transgride a disposição tradicional do livro, ao recusar a comunicação imediata, apresentando uma maneira diferente de sentir o mundo. Deste modo, com M. Butor, a literatura afirma-se verdadeiramente como um combate contra os preconceitos, contra a estupidez, contra as convenções.

Face à dificuldade de classificar este livro, tendo em conta o seu estatuto no seio da arte moderna, deveremos encará-lo com um todo: há uma osmose, um casamento entre duas artes, entre dois textos que se complementam de forma harmoniosa. Trata-se de uma escrita de experimentação onde se misturam artes completamente diferentes. 
Este hibridismo, esta "polyphonie des pratiques signifiantes" (BUTOR, s/d) leva-nos a concluir que "l'œuvre sera cette totalité prête à accueillir toutes les différences, fussent-elles les plus extrêmes" (SICARD, 1984: 55). 


\section{Bibliografia}

ABRAHAM, Sylvie (s/d). "Livre-Objet et matière à lecture”. In: Butor et l'Amérique. (Colloque de Queen's University — textes réunis et présentés par Mireille Calle-Gruber). Paris/Montréal: L'Harmattan, pp. 151-158.

BARTHES, Roland (1970). S/Z. Paris: Seuil.

Belzane, Guy (1996). "Pour une esthétique de la déception”. In: Poétique, n. 105, pp. 55-69.

Butor, Michel (s/d). Curriculum Vitae. Entretiens avec André Clavel. Paris: Plon.

Butor, Michel (1969). Les Mots dans la Peinture. Paris: Flammarion / Genève: Les Sentiers de la Création - Éditions d'Art Albert Skira.

BuTOR, Michel (1984) "Ça marche. Entretien avec Michel Butor". In: Écrire avec Butor, Grenoble: TEM - Texte en main, n.o 2, pp. 5-19.

Butor, Michel (1991). Le Temps Découpé (Collages de Thierry Renard). Paris: ELA La Différence.

ButoR, Michel (1993). Improvisations sur Michel Butor - L'écriture en transformation. Paris: ELA La Différence.

BANCQUART, Marie-Claire \& CAHNÉ, Pierre (1992). Littérature Française $d u X X^{\text {ème }}$ Siècle, Paris: P.U.F.

GAUDEMAR, Antoine de (1996). "Butoroscope”. In: Livres (14/11/1996), pp. I-III.

LA CHANCE, Michaël (s/d). “Une écriture matérielle”. In: Butor et l'Amérique. (Colloque de Queen's University - textes réunis et présentés par Mireille Calle-Gruber). Paris/Montréal, L'Harmattan, pp. 103-111.

LEMAÎTRE, Henri (1994). Dictionnaire Bordas de Littérature Française. Paris: Bordas.

REID, Martine (1994). "Bricolage: an interview with Michel Butor". In: Yale French Studies. Boudaries:

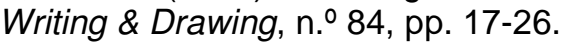

RENARD, Thierry (2000), Entrevista de 02 de Abril de $2000^{17}$.

SICARD, Michel, (1984). "A la carte - Cartes Postales Découpées”. In: Écrire avec Butor, Grenoble, TEM - Texte en main, n.ำ 2, pp. 51-70.

\footnotetext{
${ }^{17}$ Entrevista levada a cabo por Carla Pereira Fonseca e Francisco Sousa Neto, para o e-mail de Thierry Renard (collage@skynet.be), no âmbito do trabalho elaborado, sob orientação da Prof ${ }^{a}$ Doutora Maria Eduarda Keating, para o Seminário de Literatura Comparada (Literatura - Pintura) do Mestrado em Literatura Francesa da Faculdade de Letras da Universidade de Coimbra.
} 